\title{
Development Of Convenience Store System In Japan: Toward The Synchronization Of Production And Distribution
}

\author{
Hisao Fujimoto, (E-mail: fujimoto@osaka-ue.ac.jp), Osaka University of Economics, Japan
}

\begin{abstract}
This paper presents a finding from a case study of the convenience store system in Japan. Based upon two theories, strategic network theory and postponement-speculation theory, the evolutionary process of the supply chain management in the convenience store system is explained. Seven Eleven Japan, which is one of the large convenience store chains, has been developing its advanced system for several merchandise categories. This system is beyond the boundary of convenience store chains. The synchronization of production and distribution is persistently being aimed under the condition of the instantaneous consumption.
\end{abstract}

\section{INTRODUCTION}

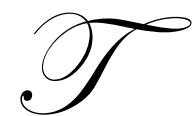

he business network and the strategic alliance have been widely discussed issue in recent business and marketing literature. It also has provided firms with new competitive advantages. These competitive advantages will be gained not from the single firm, but from the network. Further, the dimension of recent competition has moved to the dimension of time and speed with the lean manufacturing and logistic systems. The members of distribution channel are aiming for the lean supply chain with- out reducing the consumer benefits.

This paper presents an introductory finding from a case study of the convenience store system in Japan. Based upon two theories, strategic network theory and postponement-speculation theory, the evolutionary process of supply chain in the convenience store system is explained.

Despite of the emerging development of the electronic commerce and virtual mall, many retailers still have been holding merchandises in their stores as inventories. For selling these merchandises, retailers have to find customers by their marketing efforts. It means the demand or market creation. In addition to this positive action, retailers are also estimating and forecasting the customers' demands or purchasing behaviors based on the past purchasing data. Given the probabilistic estimation of consumers' purchasing behaviors, retailers have been trying to minimize inventories and/or keep the proper level of inventories. This is, however, the passive adaptation strategy adjusted by the backward inventory holdings. It has a possibility to emerge the order backlog and out-of-stock for the good sellers, and the excessive inventories for the poor sellers.

\section{POSTPONEMENT INVENTORY STRATEGY OF CONVENIENCE STORE SYSTEM}

Seven Eleven Japan, which is one of the large convenience store chains, has been developing its advanced system for several merchandise categories. This system is beyond the boundary of convenience store chains. It has been including many suppliers as merchant wholesalers and manufacturers. The inventory compression can be attained on the interorganizational system with these suppliers. It is aiming for the synchronization of the production of manufactures, the logistics, and the inventory holdings with the consumers' purchasing behaviors.

Retailers are usually doing business with the merchandise inventory. They cannot avoid a risk from the inventory holding, because the inventory consists of merchandise with the uncertainty of sales. For retailers, holding inventory means that they have to order and stock the uncertain merchandise speculatively. Recently, however, there have been appearing retailers who attempt to build "the postponement-oriented system". This system is aiming for postponing the risk by holding inventory until the latest possible time. 
As the postponement strategy of retailer is advanced, the risk of inventory holding that used to been taken by retailer has to be laid on wholesalers and /or manufacturers. This may give rise to serious problems depending on their transactional relationships. Manufacturers who take the push strategy in their distribution channels may want retailers hold large inventories. Although retailers demand the postponement of their inventory holdings, manufacturers may refuse it except for their benefit. The focal problem is how retailers can reduce the possible risk of inventory holding with the vendors' agreement.

In the recent turbulent and competitive environment, many retailers and manufacturers in the marketplace are inclined to adopt postponement strategies. The successful implementation of postponement strategy heavily depends on the ability to form and coordinate the network organization (Van Hoek, Commandeur, and Vos 1998). It also depends on the clarity of roles and shared norms based on the information technology (Deeter-Schmeltz 1997). As for the organizational systems, information technology has become a key issue for interorganizational systems. Recent developments of EDI reflect the competitive importance of information technology in channel relationships (Walton 1994; O'Callaghan et al. 1992). It is capable to make a breakthrough and take a competitive advantage in several aspects for channel partners (Wang and Seidman 1995; Holland et al. 1991). This means EDI has become a basic infrastructure or a must for firms in the 1990s (Williams et al 1998). The development of EDI may certainly continue with a higher information technology in the 2000s.

The development process of Seven Eleven Japan, which differs definitely from seven Eleven in USA, is the fact that Seven Eleven Japan has been developing the system involving its vendors (Kawabe, 1994). The first step for developing the system started with the reforming of its distribution and logistics system. It resulted to construct the frequent and small-lot delivery system of multi-items. The introduction of the electronic ordering system, the intensification of relationships with vendors, the collaborated logistic system, and the introduction of the point of sales system were attained in this new system.

The second step was the alliances with manufacturers in merchandise categories of daily foods. Fresh lunch boxes, rice balls, sandwiches, and delicatessen were included in these merchandise categories, which were correspond to the instantaneity of consumption aforementioned. While all of alliances have not been in success, almost alliances have brought the compression of inventories, the reduced loss of sales opportunities, and product developments and assortments in response to consumers' needs, all of which were base on information sharing with manufacturers and suppliers.

It also has reduced two types of risk. The first type is from the excessive holding of inventories. In past, Japanese retailers believed that the more inventories they had, the more sales they could attain. For them, retailers holding small amount of inventories reflected their weak competitive powers and passive strategies. The second type of risk is from the out-of-stock of merchandises. This brings the sales opportunity loss for retailers, and the disappointment and dissatisfaction for customers. For Seven Eleven Japan, the higher accuracy of ordering was thought to bring the reduction of two types of risk and increased customer's satisfaction. In this sense, the convenience store system of Seven Eleven Japan has been a trial to combine the just-in-time assortments for customers and the just-in-time supplies from vendors. This also means the postponement strategy and reduced inventories in the total supply chain and storefront.

\section{CHARACTERISTICS OF CONVENIENCE STORE SYSTEM}

One of the remarkable developments of marketing channels in merchandise categories of foods and grocery may be ECR. Under the concept of ECR, the distribution channel flows, which include merchandises, inventories, transactions, and information, have to be integrated and adjusted to the final consumer needs. ECR extends beyond supply chain integration to include not only more efficient replenishment, but also more efficient store assortment, promotion, and new product development. There needs the integrated system to attain the rapid and proper flow of merchandises. This can be possible on the information technology, which enables to advance communication capabilities of the transmission of information and data. It attains the strategies of cost minimization, value-added maximization and control/flexibility enhancement Two types of flexibility can be suggested. The first is product flexibility. It has to be immediately visible to the customer and is the ability to handle difficult, nonstandard orders, to meet special customer specifications. The second is volume flexibility. It is the ability to effectively increase or decrease aggregate production in response to customer demand. Their dimensions of supply chain flexibility incline to the manufacturing aspects. Along with our discussion of retailers, these two types of flexibility have to include the proper assortments of merchandises for customers' needs. The basic concepts of ECR, "proper place, proper volume, and proper timing", have to be reminded. 
Convenience stores have to make a decision, which attains the ideal merchandise assortments in the limited shelf space. It will be easy to be attained in the situation that the production and stocking can be carried out after the settlement of consumers' demands. However, these have to be carried out in advance on the estimation of consumer's shopping behavior. First, this effort has crucial importance for the competitive advantage of convenience store, because of the efficiency that comes from the minimization of inventory and the total logistic system. Secondly, convenience stores are demanded to respond to the instantaneous consumption, which means the short lead-time of consumer needs.

The purchasing and consuming process of consumers can be divided three phases. The first phase is the decision making, which is the stage to determine what the consumer buy. The second phase is the actual purchasing, which is the stage to go shopping trip to get merchandises. The third and last phase is the consuming, which is the stage to consume the purchased merchandises. Each phase may have its inherent time to perform the task. The time for consumers consists of the total time of these three phases. It may vary among merchandises and consumers. The instantaneity of consumption means the case in that the total time for consumers is very short. Convenience stores are corresponding to this instantaneity of consumption. As a result, main good seller items of convenience stores are the merchandises corresponding to the instantaneity of consumption. Convenience stores are aiming for the assortment of merchandises and services, which corresponds to the short cycle of consumer needs. Consumers are very sensitive to the freshness of merchandises, which convenience stores hold as inventories. The ultimate, and probably ideal, goal is to pursuit the synchronization of production, supply, logistics, and purchasing in the storefront.

\section{CONCLUDING REMARKS}

The finding from a case study is that the total supply chain in the convenience store system is an evolutionary new system. The synchronization of production and distribution is persistently being aimed under the condition of the instantaneous consumption. The physical inventories have been compressed and substituted with information. The accurate information may absorb uncertainties without inventories. For this purpose, the information sharing with vendors is necessary. This means the vendor monitors the buyer's inventory levels and controls the randomness and uncertainty of demands by his own decision-making. While the innovative aspect of this evolutionary system will provide convenience stores with competitive advantage, all aspects of supply chain have not been in successful. The variety of merchandises in convenience stores means that a convenience store has to transact with various vendors and manufacturers. The concept of the synchronization of production and distribution brings us the important issues to explore the dynamics and changing process of the structure of marketing channels.

\section{REFERENCES}

1. Alderson, Wroe. 1957. Marketing Behavior and Executive Action. Homewood: Richard D. Irwin.

2. Bowersox, Donald J. and Patricia J. Daugherty. 1995. Logistics Paradigms: The Impact of Information Technology. Journal of Business Logistics 16 (1): 65-80.

3. Bucklin, Louis P. 1965. Postponement, Speculation, and the Structure of Distribution Channels. Journal of Marketing Research 2 (February): 26-31.

4. Daugherty, Patricia, Matthew B. Myers, and Chad W. Autry. 1999. Automatic Replenishment Programs: An Empirical Examination, Journal of Business Logistics 20 (2): 63-82.

5. Deeter-Schmelz, Dawn R. 1997. Applying Teams to Logistics Processes: Information Acquisition and the Impact of Team Role Clarity and Norms. Journal of Business Logistics 18 (1): 159-178.

6. Dröge, Cornelia and Richard Germain. 1998. The Just-In-Time Inventory Effect: Does It Hold under Different Contextual, Environmental, and Organizational Conditions? Journal of Business Logistics 19 (2): 53-71.

7. Holland Cris, Geoff Lockett, and Ian Blackman. 1991. Planning for Electronic Data Interchange. Strategic Management Journal 13 (October): 539-550.

8. Kawabe, Nobuo 1994. Seven-Eleven No Keieishi (Managerial History of Seven-Eleven). Tokyo: Yuhikaku.

9. Lambert, Douglas M., Margaret A. Emmelhainz, and John T. Gardner. 1999. Building Successful Logistics Partnerships. Journal of Business Logistics 20 (1): 165-181.

10. Lewis, Ira and Alexander Talalayevsky. 1997. Logistics and Information Technology: A Coordination Perspective. Journal of Business Logistics 18 (1): 141-157.

11. Murphy, Paul R., James M. Daley, and Patricia K Hall. 1998. EDI Issues in Logistics: A User and Carrier Perspective. Journal of Business Logistics 19 (2): 89-102.

12. O'Callaghan, Ramon, Patrick J. Kaufmann. 1992. Adoption Correlates and Share Effects of Electronic Data Interchange Systems in Marketing Channels. Journal of Marketing 56 (April): 45-56. 
13. Pagh, Janus D., and Martha C. Cooper. 1998 Supply Chain Postponement and Speculation Strategies: How to Choose the Right Strategy. Journal of Business Logistics 19 (2): 13-32.

14. Schmitz Whipple, Judith, Robert Frankel, and Kenneth Anselmi. 1999. The Effect of Governance Structure on Performance: A Case Study of Efficient Consumer Response. Journal of Business Logistics 20 (2): 43-62.

15. Van Hoek, Remko I., Harry R. Commandeur, and Bart Vos. 1998. Reconfiguring Logistics Systems Through Postponement Strategies. Journal of Business Logistics 19 (2): 33-54.

16. Vickery, Shawnee, Roger Calantone and Cornelia Dröge. 1999. Supply Chain Flexibility: An Empirical Study. Journal of Supply Chain Management (Summer): 16-24.

17. Walton, Lisa Williams. 1994. Electronic Data Interchange (EDI): A Study of its Usage and Adoption within Marketing and Logistics Channels. Transportation Journal 34 (Winter): 37-45.

18. Wang, Eric T. C. and Abraham Seidman. 1995. Electronic Data Interchange: Competitive Externalities and Strategic Implementation Policies. Management Science 41 (March): 401-418.

19. Williams, Lisa R., George D. Magee, and Yoshinori Suzuki. 1998. A Multidimensional View of EDI: Testing the Value of EDI Participation to Firms. Journal of Business Logistics 19 (2): 73-87.

20. Yahagi, Toshiyuki. 1994. Konbiniensu Sutoa Sisutemu No Kakushinsei (Innovation of Convenience Store System). Tokyo: Nihonkeizaishinbunsha.

21. Yahagi, Toshiyuki. 1996. Seihantougo No Shoten (Focus of Alliance between Manufacturer and Distributor). In Ishihara, T. and J. Ishii eds. Seihantougou (Alliance between Manufacturer and Distributor). Tokyo:

Nihonkeizaishinbunsha: 205-234. 